\title{
Recombinant Human Bone Morphogenetic Proteins- 4 Enhanced the Tendon-to-bone Attachment Healing in a Murine Model of Rotator Cuff Tear: A Randomized Controlled Trial
}

\section{Huabin Chen}

Department of Sports Medicine, Research Center of Sports Medicine, Xiangya Hospital, Central South University, Changsha, Hunan, PR China https://orcid.org/0000-0002-6263-7002

\section{Zhanwen Wang}

Department of Sports Medicine, Research Center of Sports Medicine, Xiangya Hospital, Central South University, Changsha, Hunan, PR China

\section{Li Zhou}

Department of Orthopedic Center, Kunshan Hospital of Traditional Chinese Medicine, Suzhou, China; Department of Sports Medicine, Research Center of Sports Medicine, Xiangya Hospital, Central South University, Changsha, Hunan, PR China

\section{Bing Wu}

Department of Sports Medicine, Research Center of Sports Medicine, Xiangya Hospital, Central South University, Changsha, Hunan, PR China

\section{Hongbin Lu}

Department of Sports Medicine, Research Center of Sports Medicine, Xiangya Hospital, Central South University, Changsha, Hunan, PR China

\section{Ciliu Zhang}

Department of Pediatrics, Xiangya Hospital, Central South University, Changsha, Hunan, PR China Tao Zhang ( $\square$ ztblack@csu.edu.cn )

Department of Sports Medicine, Xiangya Hospital, Central South University, Changsha, Hunan, PR China;

\section{Research}

Keywords: Bone Morphogenetic Proteins-4, Tendon-to-bone attachment, chondrogenesis, rotator cuff healing

Posted Date: September 23rd, 2020

DOI: https://doi.org/10.21203/rs.3.rs-76730/v1 
License: (c) (i) This work is licensed under a Creative Commons Attribution 4.0 International License. Read Full License 


\section{Abstract}

Background: Injuries on tendon-to-bone attachment (TBA) are common clinical dilemmas. Bone Morphogenetic Proteins-4 (BMP-4) has been found the potency in chondrogenesis. But there is rare studies focusing the influence of BMP-4 on the TBA healing. Thus, the objective of this study was to explore the effect of BMP-4 on the healing of TBA in murine model of rotator cuff tear.

Methods: 120 mature C57BL/6 mice (12 weeks old) were randomly divided into BMP-4 group, noggin (an inhibitor of all BMP activities) group and control group after being established an injury model of supraspinatus tendon insertion. At week 2 and 4 after surgery, the supraspinatus tendon- humerus complex (SSTHC) were harvested for microradiographic, histologic, immunofluorescent and biomechanical evaluations.

Results: Radiographic data showed that BMP-4 was able to improve the quality of subchondral bone, manifested as higher BV/TV, Tb.N, TB.Th, and lower Tb.Sp. Histologically, the BMP-4 group at week-2 and -4 showed better BTA healing interface, characterized by better organizational integration and remodeling, thicker fibrocartilage layer and more fibrocartilage cells. Immunoflorescence evaluation demonstrated the number of SOX 9 positive cells in the BMP-4 group was significantly more than that in the control or noggin group at postoperative weeks 2 and 4 ( $p<0.05$ for all). Mechanical testing results demonstrated the failure load and stiffness in the BMP-4 group were significantly higher ( $p<0.05$ for both), while in the noggin group were lower ( $p<0.05$ for both), compared to the control group at postoperative weeks 4 .

Conclusion: BMP-4 might enhance the TBA healing by promoting the regeneration of fibrocartilaginous enthesis and mineralization, while noggin inhibited this process.

Clinical Relevance: BMP-4 may be a potential therapy to augment TBA healing, and finally lead to more rapid rehabilitation and reduce risk of recurrent repair.

\section{Introduction}

Tendon-to-bone attachment (TBA) transfers the force from muscles to bone during body movement, and the structure comprises four distinct yet continuous zones: tendon, nonmineralized fibrocartilage, mineralized fibrocartilage, and bone [1-4]. TBA injuries are common clinical dilemmas, such as rotator cuff tear. Unfortunately, regeneration of the special tissues, particularly the native fibrocartilaginous enthesis, is inability, partly due to the vastly different mechanical properties of the two materials. Surgical repair of the structure is attaching the tendon to bone via anchors, and the tendon is healed to bone via a fibrovascular scar tissue, which has inferior biomechanical properties. Therefore, the repair of rotator cuff tear in clinic is reported a re-rupture rate of $10 \%$ to $28 \%$ from minor to large tears [5]. Numerous therapies are attempted to regenerate the native fibrocartilaginous enthesis, such as physical therapy, stem cells, biomechanical scaffolds, and biologic agents, but either achieved only a limited success [6, 7]. 
A better understanding of the fundamental mechanism of TBA healing may provide new approaches to facilitate healing. Bone morphogenetic protein 4 (BMP-4), a member of bone morphogenetic proteins, is well known for its acceleration on inducing bone formation. However, more and more researches demonstrated the potential for BMP-4 to promote chondrogenesis [8-10]. Recombinant human BMP-4 (rhBMP-4) was found to stimulate chondrogenesis in limb bud by inducing the production of cartilage matrix, which was important to maintain the cartilage phenotype. The rhBMP-4 could successfully promote the initial differentiation of mesenchymal stem cells (MSCs) in vitro to become chondroprogenitor lineage and induce differentiation into mature chondrocytes [11]. Muscle derived stem cells (MDSCs), expressed BMP-4, were able to promote cartilage regeneration in a murine articular cartilage defect model, without degrade or ossify up to 6 months postoperatively [8]. When delivery the MDSCs expressing BMP-4 and sFlt1 with platelet rich plasma (PRP) to articular cartilage repair, the collagen synthesis was promoted, chondrocyte apoptosis was suppressed, and finally the repair process was enhanced [12]. Moreover, when MSCs were co-treated with TGF- $\beta$ and BMP-4, chondrogenesis was further improved via shortening the duration of the SOX 9 protein decline [13]. The role of BMP-4 in chondrogenesis, therefore, was thought significant, and it might be a promising therapy for cartilage defects [11]. However, it is still unknown whether BMP-4 can enhance the formation of fibrocartilaginous enthesis in the attachment between rotator cuff tendon and humur after its surgical repair. Since chondrogenesis also plays a crucial role in the TBA healing, we hypothesize that BMP-4 may be involved in the TBA healing and regulate the regeneration of enthesis.

The goal of this study was to investigate the role of BMP-4 on augmenting the TBA healing. In this study, the effect of rhBMP-4 and noggin (an inhibitor of all BMP activities) were detected in a murine rotator cuff repair model, with respect to the micro-computed tomography (micro-CT), histomorphology and biomechanical properties.

\section{Materials And Methods}

\section{Study design}

Total of 120 mature (12 weeks) male C57BL/ 6 mice were used in this study, and a rotator cuff repair model were established in the left forelimb, following Scott A. Rodeo's method [14]. The operated mice were randomly allocated to 1 of 3 groups: control $(n=40)$, rhBMP-4 $(n=40)$, and noggin $(n=40)$, intervened with fibrin sealant, fibrin sealant containing rhBMP-4 (Bio-tool, Beijing), and fibrin sealant containing noggin (Huabio, Hangzhou), respectively. Due to the ineffectivity of fibrin sealant to rotator cuff repair in a rodent model [15], the natural healing group was cancelled in this study. Animals were housed in cages and allowed unrestrained cage activity after surgery. At postoperative 2 and 4 weeks, mice were sacrificed and bilateral supraspinatus-supraspinatus tendon-humerus (SSTH) complexes were harvested for subsequent detections (Figure 1).

\section{Fibrin sealants preparation and in vitro drug sustained-release test}


Fibrinogen solution (Sigma-Aldrich) and thrombin solution (Sigma-Aldrich) were prepared following the manufacturer's manual. RhBMP-4 and noggin were added to the thrombin solution, respectively. $10 \mu \mathrm{L}$ fibrinogen solution and $2 \mu \mathrm{L}$ thrombin solution (containing $0.5 \mu \mathrm{g}$ rhBMP-4 or $0.2 \mathrm{ng}$ noggin, the dosage used in prior studies $[16,17]$ ) were utilized to make each fibrin sealant, with a $0.22 \mu \mathrm{m}$ syringe filter (Millex, Sigma). Similarly, fibrin sealant in control group was also prepared, but containing nothing.

To measure BMP-4 and noggin release kinetics from the fibrin sealant, which was comprised of $250 \mu \mathrm{L}$ fibrinogen solution and $50 \mu \mathrm{L}$ thrombin solution, and $12.5 \mu \mathrm{g}$ rhBMP-4 or $5 \mathrm{ng}$ noggin. The gels were incubated $0.5 \mathrm{~mL}$ phosphate buffered saline (PBS) with $10 \%$ fetal bovine serum at $37{ }^{\circ} \mathrm{C}$. The PBS solution was replaced and collected five times over the first 24 hours, and then was changed and collected daily. ELISA for BMP-4 and noggin were performed on the washed solutions, respectively. The release experiment was carried 3 times and cumulative percentages were presented in the results.

\section{Surgical technique}

Briefly, mice were placed in a right lateral decubitus position after being anesthetized with an intraperitoneal injection of $0.3 \%$ pentobarbital sodium. An incision was made on the left shoulder, and the deltoid muscle was revealed, which was dissected minimally to expose the supraspinatus tendon. Using a customized retractor to elevate the acromion, the supraspinatus-supraspinatus tendon (SST) was isolated. Then, the SST was sutured with a 6-0 prolene with double needles (Ethicon) in an "8" figure fashion, and sharply detached from its footprint on the humeral head. Any soft tissues and fibrocartilaginous tissues remaining on the bone were gently removed with a scalpel. One transosseous bone tunnel was then created with a 30-G needle in the humeral head under the footprint, and the two sutures limbs were crossed through the tunnel, one from lateral to the interior, and the other from interior to lateral. After tightening the two sutures limbs, the SST was reattached to the footprint. Before tying the knot, fibrin sealant, fibrin sealant containing rhBMP-4, or fibrin sealant containing noggin was placed on the tendon-to-bone interface. Finally, the wounds were layered sutured, and buprenorphine $(0.05 \mathrm{mg} / \mathrm{kg})$ was administrated subcutaneously for analgesic postoperatively. All animal surgeries were operated by two sports medicine doctors under surgical microscopy.

\section{Micro-computed tomography (micro-CT) evaluation}

Micro-CT (viva CT 80; Scanco Medical, Switzerland) was performed in this study to assess the new bone formation at the tendon attachment site. After fixing in $10 \%$ paraformaldehyde in $4{ }^{\circ} \mathrm{C}$ for 24 hours, each specimen was kept in a tube surrounded by formalin and scanned with $10.4 \mu \mathrm{m}$ voxel size, at $55 \mathrm{KVp}$, $0.36^{\circ}$ rotation step $\left(180^{\circ}\right.$ angular range) and a $400 \mathrm{~ms}$ exposure per view. Then data of each specimen were processed with a 3-dimensional Gaussian filter and a global threshold, to identify the bone voxels from the surrounded saline in bone marrow and soft tissues. After thresholding, the micro-parameters of the osteogenesis at TBA were calculated, including bone volume fraction (BV/TV), trabecular number (Tb.N), trabecular thickness (Tb.Th) and trabecular spacing (Tb.Sp). The region of interest (ROI) was selected randomly under the footprint, at the center of the two suture bone holes in the image. In the 
analysis, the ROI was defined as a cube with a length of $1 \mathrm{~mm}$, from the bone surface and extending distally, so as to avoid involvement of adjacent cortical bone.

\section{Histomorphometric analysis}

Once dissection, the fresh SSTH structures were fixed in 10\% neutral buffered formalin for 48 hours. After 7 days decalcification in 10\% EDTA, the specimens were dehydrated in grade ethanol, and embedded in paraffin. The paraffin blocks were sectioned with $5 \mu \mathrm{m}$ thickness in the coronal plane, through the supraspinatus tendon and the greater tuberosity.

The sections were stained with Hematoxylin and eosin (H\&E, Solarbio Co. Ltd, Beijing, China) and Toluidine blue-fast green (Sigma-Aldrich, St. Louis, MO). H\&E stained sections were used for the histological description of healing of BTI, and semi-quantitative analysis for cell density around the tendon to bone interface [15]. Toluidine blue $0 /$ fast green (TB) stained sections were used for semiquantitative analysis for the fibrocartilage zone thickness using the ImageJ software (National Institutes of Health, Bethesda, Maryland) [18]. All sections were observed using a transmitted light microscopy (Olympus CX31; Olympus Inc) under a same condition.

\section{Immunoflorescence analysis}

Immunoflorescence was used to detect SOX 9 expressing cells in the interface zone of tendon to bone. After fixation, decalcification, dehydration and embedded in OCT, the SSTHC specimens were longitudinally sectioned with $10 \mu \mathrm{m}$. For immunofluorescence staining, the sections were washed with PBS, permeabilized with $0.1 \%$ TritonX-100, and blocked with $5 \%$ bovine serum albumin (BSA; SigmaAldrich, St. Louis, MO). Then, primary antibody against mouse SOX 9 (ab76997, abcam) was applied at $4^{\circ} \mathrm{C}$ overnight, subsequently incubated with anti-rabbit secondary antibody (ab150116, abcam) at room temperature for 1 hour, and finally incubated with DAPI (ab228549, abcam). All the images were observed and captured with using a Zeiss Axio Imager (Zeiss, Solms, Germany). To quantitate the positive signals of SOX 9, a region of interest (ROI) was defined at the SST attachment site according to aprevious similar study[19]. The SOX 9 positive cells areas were counted for three times, and the mean number per square millimeter for each sample was reported. The assessor was blinded to the groups during image analysis.

\section{Biomechanical testing}

For biomechanical testing, each SSTHC was carefully dissected from surrounding tissues under a surgical microscope, and stored at $-80^{\circ} \mathrm{C}$. At the time of conduct of testing, the specimen was thawed at room temperature, and the supraspinatus muscle and all suture were carefully removed. Each SSTHC was dipped in $0.9 \%$ saline solution water bath at $37^{\circ} \mathrm{C}$ before biomechanical testing. The humerus was mounted and the supraspinatus tendon was fixed in custom grip with sandpaper and ethyl cyanoacrylate. A microcomputer controlled electronic material testing system (WD-T, Shanghai Zhuoji Instrument Equipment Co., Ltd.) was used to test the failure load of TBA. The SSTHC was placed in the testing system machine and allowing a uniaxial tensile following approximate the anatomic position of 
the supraspinatus tendon. After pre-tensioning for 3 times under a preload between 0.0-0.5 N, the SSTHC was loaded to failure at a rate of $1 \mathrm{~mm} / \mathrm{min}$, and the ultimate failure load was recorded. The stiffness was calculated from the curve of load to deformation.

\section{Statistical Analysis}

Statistical analysis was performed using GraphPad Prism (Version 6.0.1; San Diego, CA, USA). All quantitative data were presented as mean \pm SD (standard deviation) and analyzed statistically using 2way analysis of variance (ANOVA) with the Bonferroni post hoc test to detect differences among groups. The significant level was sat to $P<0.05$.

\section{Results}

All animals tolerated the surgery and without any perioperative complications. Either group showed no gross failures.

\section{In vitro release kinetics}

Sustained release of BMP-4 and noggin were achieved through the use of fibrin gel system. In the first 24 hours, $(19.6 \pm 2.4) \%$ and $(21.2 \pm 2.4) \%$ of the BMP-4 and noggin were released into the PBS-FBS solution, respectively. At the end of 14 days, nearly $(98.6 \pm 4.3) \%$ and $(99.1 \pm 4.3) \%$ of the total BMP-4 and noggin were released into the solution (Figure 2).

\section{Micro-CT evaluation}

The three-dimensional morphologic of the SSTH was constructed (Figure 3) and the microstructural parameters of the subchondral bone at the attached interface were analyzed (Table 1). The microstructure data showed that the BMP-4 group had significant greater BV/TV $(0.551 \pm 0.075), \mathrm{Tb} . \mathrm{N}$ $\left(12.225 \pm 1.830 \mathrm{~mm}^{-1}\right)$ and Tb.Th $(0.051 \pm 0.0031 \mathrm{~mm})$ at postoperative 4 weeks than the control group (BV/TV: $0.458 \pm 0.084, p<0.01$; Tb.N: $9.864 \pm 1.730 \mathrm{~mm}^{-1}, p<0.05$; Tb.Th: $0.046 \pm 0.0032 \mathrm{~mm}, p<0.05$ ), while there was no difference at 2 weeks for both (BV/TV: $0.430 \pm 0.039$ vs. $0.381 \pm 0.033, p>0.05$; Tb.N: $9.108 \pm 1.143 \mathrm{~mm}^{-1}$ vs. $7.255 \pm 1.238 \mathrm{~mm}^{-1}, \mathrm{p}>0.05$; Tb. Th: $0.036 \pm 0.0037 \mathrm{~mm}$ vs. $0.034 \pm 0.0028 \mathrm{~mm}$, $p>0.05)$. In the noggin group, the BV/TV ( $2 w: 0.275 \pm 0.027 ; 4 w: 0.357 \pm 0.034), T b . N(2 w: 5.013 \pm 1.308$ $\left.\mathrm{mm}^{-1} ; 4 \mathrm{w}: 7.310 \pm 1.253 \mathrm{~mm}^{-1}\right)$ and Tb.Th $(2 \mathrm{w}: 0.029 \pm 0.0024 \mathrm{~mm} ; 4 \mathrm{w}: 0.041 \pm 0.0033 \mathrm{~mm})$ were significant lower than the control group ( $2 w$ : $p<0.01$ for BV/TV; $p<0.05$ for Tb.N and Tb.Th; $4 w$ : $p<0.05$ for BV/TV, Tb.N and Tb.Th) and BMP-4 group ( $<<0.05$ for BV/TV, Tb.N and Tb.Th in both week-2 and -4) both at postoperative 2 and 4 weeks. In addition, the Tb.Sp in the noggin group ( $2 \mathrm{w}: 0.162 \pm 0.014 \mathrm{~mm}$; $4 \mathrm{w}: 0.156 \pm 0.013 \mathrm{~mm}$ ) were higher than that in the control group ( $2 \mathrm{w}: 0.147 \pm 0.018 \mathrm{~mm}, \mathrm{p}>0.05 ; 4 \mathrm{w}$ : $0.134 \pm 0.017 \mathrm{~mm}, \mathrm{p}<0.05)$ at week-4 and BMP-4 group $(2 \mathrm{w}: 0.138 \pm 0.011 \mathrm{~mm}, \mathrm{p}<0.05 ; 4 \mathrm{w}: 0.112 \pm 0.012$ $\mathrm{mm}, \mathrm{p}<0.01)$ at week-2 and -4 .

\section{Histomorphometry}


H\&E staining showed that supraspinatus tendon was healed to the humeral head, and the enthesis was gradually regenerated with time. At postoperative 2 weeks, tissue connected tendon and bone was fibrovascular, which was poorly organized and highly cellular in all groups. In the BMP-4 and control group, there were some cartilage-like cells in the attachment zone, which was rare in the noggin specimens. The mean cell density in the TBA was lower in the BMP-4 groups $\left(5425 \pm 683 \mathrm{cells} / \mathrm{mm}^{2}\right.$, $p<0.05)$, and there was no significant difference between the noggin group $\left(6825 \pm 790 \mathrm{cells} / \mathrm{mm}^{2}\right.$, $\mathrm{p}>0.05)$ and control group $\left(6539 \pm 720\right.$ cells $\left./ \mathrm{mm}^{2}\right)$ at week 2 . At postoperative 4 weeks, remolding was observed in the attachment and an enthesis reformed, characterized with prevalent fibrocartilage cells occurrence between the tendon and bone. Mean cell density in the TBA was also lower in the BMP-4 group (4339 \pm 544 cells $\left./ \mathrm{mm}^{2}, p<0.05\right)$, but higher in the noggin group $\left(6428 \pm 605 \mathrm{cells} / \mathrm{mm}^{2}, \mathrm{p}<0.05\right)$, when compared to the controls ( $5410 \pm 582$ cells $/ \mathrm{mm}^{2}$ ) at week 4 . In addition, the mean cell density in the noggin group was significantly higher than that in the BMP-4 group at week-2 and $-4(P<0.01)$.

TB staining showed that some TB deposited at the attachment site, which indicated formation of fibrocartilage. At postoperative 2 weeks, the thickness of fibrocartilage zone in the noggin group $(7.7 \pm 1.3$ $\mu \mathrm{m}, \mathrm{p}<0.05)$ was lower than the control group $(16.4 \pm 3.3 \mu \mathrm{m})$, while there was no significant difference between the BMP-4 group $(19.1 \pm 4.7 \mu \mathrm{m}, \mathrm{p}>0.05)$ and the control group. At postoperative 4 weeks, the BMP-4 group $(44.5 \pm 8.4 \mu \mathrm{m}, \mathrm{p}<0.05)$ had thicker fibrocartilage zone, and the noggin group $(28.3 \pm 4.8$ $\mu \mathrm{m}, \mathrm{p}<0.05)$ was thinner, compared with the control group $(36.0 \pm 6.2 \mu \mathrm{m})$. Furthermore, the thickness of fibrocartilage zone in the BMP-4 group was obviously thicker than that in the noggin group at postoperative week-2 and $-4(p<0.01)$.

\section{Immunoflorescence analysis}

Immunoflorescence evaluation for SOX 9 (Figure 5) showed that SOX 9 positive cells were significantly more in BMP-4 group ( $2 \mathrm{w}: 73.2 \pm 6.7$ cells $/ \mathrm{mm}^{2}, \mathrm{P}<0.05 ; 4 \mathrm{w}$ : $286.4 \pm 15.2$ cells $\left./ \mathrm{mm}^{2}, \mathrm{P}<0.05\right)$ than that in the control group ( $2 \mathrm{w}$ : $41.2 \pm 5.1$ cells $/ \mathrm{mm}^{2}, \mathrm{P}<0.05 ; 4 \mathrm{w}$ : $\left.253.8 \pm 13.6 \mathrm{cells} / \mathrm{mm}^{2}, \mathrm{P}<0.05\right)$ at both postoperative 2 and 4 weeks. On the other hand, the number of SOX $9^{+}$cells in the noggin group $(217.5 \pm$ 18.6 cells $/ \mathrm{mm}^{2}, P<0.05$ ) was less than that in the control group at week-4, and there was no significant difference between them at week-2 ( $35.6 \pm 5.4$ cells $/ \mathrm{mm}^{2}$ vs $\left.41.2 \pm 5.1 \mathrm{cell} / \mathrm{s} / \mathrm{mm}^{2}, \mathrm{P}>0.05\right)$. In addition, compared with BMP-4 group, the numbers of SOX $9^{+}$cells in the noggin group were obviously lower at both week-2 and -4 ( $P<0.05$ for both).

\section{Biomechanical Testing}

The failure site in all groups was at the tendon bone attachment during the mechanical testing. At postoperative 2 weeks, the BMP-4 group had a significant higher failure load $(p<0.05)$, and the noggin group $(p<0.05)$ had a significant lower failure load than the controls. There was no significant different stiffness in the BMP-4 group ( $>>0.05)$ and noggin group ( $p>0.05)$, when compared to the control group. At postoperative 4 weeks, both the failure load and stiffness were higher in the BMP-4 group $(p<0.05$ for both), and lower in the noggin group ( $p<0.05$ for both). In addition, the failure load and stiffness in the 
BMP-4 group were significantly higher than those in in the noggin group at postoperative week-2 and -4 $(p<0.05$ for both). All biomechanical testing data were showed in Table 1 . According to the estimation, the power of test of each outcome variable exceeded $95 \%$.

Table 1 The biomechanical properties of the PPT complex (mean \pm standard deviation)

\begin{tabular}{|c|c|c|c|c|}
\hline & \multicolumn{2}{|l|}{$2 w$} & \multicolumn{2}{|l|}{$4 w$} \\
\hline & Failure Load $(\mathrm{N})$ & Stiffness $(\mathrm{N} / \mathrm{mm})$ & Failure Load $(\mathrm{N})$ & Stiffness $(\mathrm{N} / \mathrm{mm})$ \\
\hline Control Group & $2.16 \pm 0.52$ & $1.68 \pm 0.45$ & $3.57 \pm 0.61$ & $2.80 \pm 0.75$ \\
\hline BMP-4 Group & $2.93 \pm 0.45^{\star}$ & $2.07 \pm 0.36$ & $4.34 \pm 0.75^{*}$ & $3.46 \pm 0.59^{\star}$ \\
\hline Noggin Group & $1.351 \pm 0.44^{\star \#}$ & $1.22 \pm 0.30^{\#}$ & $2.51 \pm 0.53^{\star \#}$ & $2.18 \pm 0.51^{\star \#}$ \\
\hline
\end{tabular}

${ }^{*} \mathrm{p}<0.05$, the difference from the control group at the same time point;

${ }^{\#} \mathrm{p}<0.05$, the difference from the BMP-4 group at the same time point.

\section{Discussion}

The current study showed that application of rhBMP-4 fibrin beads in the tendon bone repair interface was able to improve osteogenesis, fibrocartilage zone regeneration, and biomechanical property of the repaired enthesis in a murine model of rotator cuff repair. Combined with the lower cellular and higher SOX 9 expression, out data therefore demonstrated that BMP-4 seemed to accelerate the tendon bone attachment healing.

Chondrogenesis was a crucial factor contributing the regeneration of attached enthesis in tendon to bone injuries, and the regenerated enthesis was closed related to the biomechanical property of TBA. Histologically, this regenerated enthesis is featured by the organized fibrocartilage zone between bone and tendon [4]. Chondrocyte density and fibrocartilage zone thickness were used as important indications to evaluate the fibrocartilaginous enthesis. In the present study, we observed fibrocartilaginous enthesis formed at postoperative 2 weeks in the murine rotator cuff repair models, and fibrocartilage thickness was thicker at postoperative 4 weeks, with lower chondrocytes density. Besides, many studies have been performed to further deplore the effects of BMP-4 on chondrogenesis. BMP-4 was showed to maintain

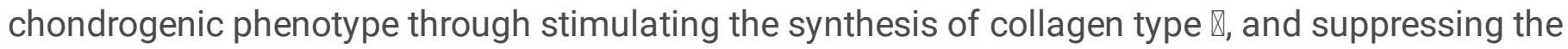
production of collagen type $\mathbb{Q}[11,20]$. This was mostly associated with the interaction between Runx2 and BMP-activated Smad1. In vitro, BMP-4 was able to facilitate the differentiation of MSCs to a chondroprogenitor lineage and induce differentiation towards mature chondrocytes[21]. During MSCs chondrogenesis, BMP-4 appeared to shorten the duration of SOX 9 protein decline $[9,13]$. In the developing mouse mandibular process, BMP-4 could induce chondrogenesis, and it was positively regulated by SOX 9 [22]. SOX 9, as the essential factor to restore the native enthesis [23], was also 
observed in the attached site of tendon to bone, and number of SOX 9 positive cells was more than the controls. Therefore, BMP-4 might be able to promote fibrocartilaginous enthesis regeneration in BTA healing, through regulating the SOX 9 mediated chondrocyte differentiation.

In addition, BMP-4 has a well-known positive effect on bone formation. Though no obvious new bone formation at the TBA site was found from the histological sections, the microstructure of trabecular bone detected by micro-CT showed there was osteogenesis at the attachment site during the healing of supraspinatus tendon to humerus. Bone volume fraction, Tb.N and Tb.Th were both higher in the BMP-4 group at postoperative 4 weeks, and noggin inhibited them. Our previous studies have confirmed the crucial role of osteogenesis in the tendon bone healing [24, 25]. BMP-4 was able to facilitate new bone formation through endochondral ossification [26], which was found as one initiating event during BTA healing in our previous studies $[18,27]$. The new bone appears to occur at the footprint, since there was some fibrous interface tissue at the attachment site, followed by mineralization. In the mature attachment, a mineral gradient fibrocartilage zone was evidenced as non-mineralized fibrocartilage and mineralized fibrocartilage. So, mineralization of the attachment was vital to regenerate a mature rotator cuff enthesis. BMP-4 in this study seemed to facilitate mineralization during the healing of TBA.

Noggin is a special molecule to prevent BMPs from interacting their receptors [28]. Noggin could inhibit BMPs induced new bone formation via decreasing collagen synthesis [29]. However, when noggin was knocked out, excess BMP activity was observed, and resulted in cartilage hyperplasia and joint formation failure, while overexpression of noggin always leaded to complete absence of skeletal elements [30]. Noggin might play a regulate and balance role on the effect of BMPs on chondrogenesis and osteogenesis. In rat anterior cruciate ligament (ACL) reconstructed models, noggin was showed to decrease new bone formation in the extent and increase fibrous scar in the tendon bone interface, but had no effect on the biomechanical properties [31]. In the present study, noggin seemed to impair the supraspinatus tendon healed to humerus, with worse mineralization and fibrocartilage formation, and weaker ultimate failure load and stiffness, at postoperative 4 weeks.

The current study has a number of limitations. First, as BMP-4 was bound to extracellular matrix components, it was very difficult to detect the exact doses of BMP-4 secreted from fibrin sealants in vivo. The release kinetics of BMP-4 and noggin in vitro clearly showed the fibrin sealant was able to provide sustained release, but it could not represent the actual release kinetics in vivo. It was possible that the release of BMP-4 and noggin in vivo was slower or faster, because the injury site in vivo was more complex. Second, though mice is a great model for supraspinatus tendon repair [14], mice are quadrupedal animals, and the mechanical stimulation after surgery is different from humans; thus, we cannot translate our finding into the rotator cuff tear repair in humans simply, more experiments are required to verify the effect of BMP-4 and noggin on TBA healing. Third, in this study all animals were allowed free activity postoperatively, but it was not match the actual management, whose operated shoulder was asked to immobilized at a extented position for several days. Finally, though all mice were operated by the same two surgeons and they were trained before the study, the inevitable variations were still inevitable. 


\section{Conclusion}

In summary, this study suggested that BMP-4 might play a vital role in the healing of tendon to bone. The results showed rhBMP-4 had a positive effect on the regeneration of fibrocartilaginous enthesis and mineralization, while noggin inhibited this process.

BMP-4 might be a potential therapy to augment TBA healing, and finally lead to more rapid rehabilitation and reduce risk of recurrent repair.

\section{List Of Abbreviations}

\begin{tabular}{|ll|}
\hline TBA & tendon-to-bone attachment \\
\hline BMP-4 & bone morphogenetic proteins-4 \\
\hline rhBMP-4 & recombinant human BMP-4 \\
\hline SST & supraspinatus tendon \\
\hline SSTHC & supraspinatus tendon- humerus complex \\
\hline MSCs & mesenchymal stem cells \\
\hline MDSCs & muscle derived stem cells \\
\hline PRP & platelet rich plasma \\
\hline micro-CT & micro-computed tomography \\
\hline PBS & phosphate buffered saline \\
\hline BV/TV & bone volume fraction \\
\hline Tb.N & trabecular number \\
\hline Tb.Th & trabecular thickness \\
\hline Tb.Sp & trabecular spacing \\
\hline ROI & the region of interest \\
\hline H\&E & hematoxylin and eosin \\
\hline TB & toluidine blue O/fast green \\
\hline ACL & anterior cruciate ligament \\
\hline
\end{tabular}

\section{Declarations}

\section{Authors' contributions}


$\mathrm{HC}$ and ZW: acquisition of data, development of methodology, analysis of data, interpretation of data, drafting the manuscript. $\mathrm{HC}$ and $\mathrm{HL}$ wrote the paper. $\mathrm{LZ}$ and $\mathrm{BW}$ : assisted in the experiments and preparation of the manuscript. TZ and CZ: study design, project administration. All authors read and approved the final manuscript.

\section{Funding}

This work was supported by the National Natural Science Foundation of China (No. 81902220), the Natural Science Foundation of Hunan Province, China (No. 2018JJ3814) and The Fundamental Research Funds for the Central Universities of

Central South University (N0.2017zzts238).

\section{Availability of data and materials}

Data sharing is not applicable to this article as no datasets were generated or analysed during the current study.

\section{Ethics approval and consent to participate}

This study was approved by the Animal Ethics Committee of Xiangya Hospital (Permitted No. 2019030490). All mice were raised in SPF grade environments in the Department of Laboratory Animals, Central South University, and were managed by full-time staff. The animal models were established by $\mathrm{H}$ Chen, and specimen were collected by B Wu. The animal operators make themselves master of the whole operation, and strictly abide by the relevant matters of animal ethics.

\section{Consent for publication}

Applicable.

\section{Competing interests}

The authors declare that they have no competing interests.

\section{Acknowledgements}

Not applicable.

\section{References}

1. Atesok K, Fu FH, Wolf MR, Ochi M, Jazrawi LM, Doral MN, Lubowitz JH, Rodeo SA: Augmentation of tendon-to-bone healing.J Bone Joint Surg Am 2014, 96:513-521.

2. Lu H, Chen C, Xie S, Tang Y, Qu J: Tendon Healing in Bone Tunnel after Human Anterior Cruciate Ligament Reconstruction: A Systematic Review of Histological Results.J Knee Surg 2019, 32:454- 
462.

3. Lu HH, Thomopoulos S: Functional attachment of soft tissues to bone: development, healing, and tissue engineering.Annu Rev Biomed Eng 2013, 15:201-226.

4. Chen C, Zhang T, Liu F, Qu J, Chen Y, Fan S, Chen H, Sun L, Zhao C, Hu J, Lu H: Effect of Low-Intensity Pulsed Ultrasound After Autologous Adipose-Derived Stromal Cell Transplantation for Bone-Tendon Healing in a Rabbit Model.Am J Sports Med 2019, 47:942-953.

5. Hein J, Reilly JM, Chae J, Maerz T, Anderson K: Retear Rates After Arthroscopic Single-Row, DoubleRow, and Suture Bridge Rotator Cuff Repair at a Minimum of 1 Year of Imaging Follow-up: A Systematic Review.Arthroscopy 2015, 31:2274-2281.

6. Depres-Tremblay G, Chevrier A, Snow M, Hurtig MB, Rodeo S, Buschmann MD: Rotator cuff repair: a review of surgical techniques, animal models, and new technologies under development.J Shoulder Elbow Surg 2016, 25:2078-2085.

7. Klouche S, Lefevre N, Herman S, Gerometta A, Bohu Y: Return to Sport After Rotator Cuff Tear Repair: A Systematic Review and Meta-analysis.Am J Sports Med 2016, 44:1877-1887.

8. Kuroda R, Usas A, Kubo S, Corsi K, Peng H, Rose T, Cummins J, Fu FH, Huard J: Cartilage repair using bone morphogenetic protein 4 and muscle-derived stem cells.Arthritis Rheum 2006, 54:433-442.

9. Jang $Y$, Jung H, Nam Y, Rim YA, Kim J, Jeong SH, Ju JH: Centrifugal gravity-induced BMP4 induces chondrogenic differentiation of adiposederived stem cells via SOX9 upregulation.Stem Cell Res Ther 2016, 7:184.

10. Zhang J, Zhu X, Kong Y, Huang Y, Dang X, Mei L, Zhao B, Lin Q, Wang J: Strontium stimulates alkaline phosphatase and bone morphogenetic protein-4 expression in rat chondrocytes cultured in vitro.J Trace Elem Med Biol 2019, 55:15-19.

11. Miljkovic ND, Cooper GM, Marra KG: Chondrogenesis, bone morphogenetic protein-4 and mesenchymal stem cells.Osteoarthritis Cartilage 2008, 16:1121-1130.

12. Mifune Y, Matsumoto T, Takayama K, Ota S, Li H, Meszaros LB, Usas A, Nagamune K, Gharaibeh B, Fu FH, Huard J: The effect of platelet-rich plasma on the regenerative therapy of muscle derived stem cells for articular cartilage repair.Osteoarthritis Cartilage 2013, 21:175-185.

13. Diederichs S, Gabler J, Autenrieth J, Kynast KL, Merle C, Walles H, Utikal J, Richter W: Differential Regulation of SOX9 Protein During Chondrogenesis of Induced Pluripotent Stem Cells Versus Mesenchymal Stromal Cells: A Shortcoming for Cartilage Formation.Stem Cells Dev 2016, 25:598609.

14. Lebaschi AH, Deng XH, Camp CL, Zong J, Cong GT, Carballo CB, Album Z, Rodeo SA: Biomechanical, Histologic, and Molecular Evaluation of Tendon Healing in a New Murine Model of Rotator Cuff Repair.Arthroscopy 2018, 34:1173-1183.

15. Wang D, Tan H, Lebaschi AH, Nakagawa Y, Wada S, Donnelly PE, Ying L, Deng XH, Rodeo SA: Kartogenin Enhances Collagen Organization and Mechanical Strength of the Repaired Enthesis in a Murine Model of Rotator Cuff Repair.Arthroscopy 2018, 34:2579-2587. 
16. Ahn SH, Kim CS, Suk HJ, Lee YJ, Choi SH, Chai JK, Kim CK, Han SB, Cho KS: Effect of recombinant human bone morphogenetic protein-4 with carriers in rat calvarial defects.J Periodontol 2003, 74:787-797.

17. Pang EK, Im SU, Kim CS, Choi SH, Chai JK, Kim CK, Han SB, Cho KS: Effect of recombinant human bone morphogenetic protein- 4 dose on bone formation in a rat calvarial defect model.J Periodontol 2004, 75:1364-1370.

18. Xu D, Zhang T, Qu J, Hu J, Lu H: Enhanced patella-patellar tendon healing using combined magnetic fields in a rabbit model.Am J Sports Med 2014, 42:2495-2501.

19. Wada S, Lebaschi AH, Nakagawa Y, Carballo CB, Uppstrom TJ, Cong GT, Album ZM, Hall AJ, Ying L, Deng XH, Rodeo SA: Postoperative Tendon Loading With Treadmill Running Delays Tendon-to-Bone Healing: Immunohistochemical Evaluation in a Murine Rotator Cuff Repair Model.J Orthop Res 2019, 37:1628-1637.

20. Dexheimer V, Gabler J, Bomans K, Sims T, Omlor G, Richter W: Differential expression of TGF-beta superfamily members and role of Smad1/5/9-signalling in chondral versus endochondral chondrocyte differentiation.Sci Rep 2016, 6:36655.

21. Ali IH, Brazil DP: Bone morphogenetic proteins and their antagonists: current and emerging clinical uses.Br J Pharmacol 2014, 171:3620-3632.

22. Semba I, Nonaka K, Takahashi I, Takahashi K, Dashner R, Shum L, Nuckolls GH, Slavkin HC: Positionally-dependent chondrogenesis induced by BMP4 is co-regulated by Sox9 and Msx2.Dev Dyn 2000, 217:401-414.

23. Nagura I, Kokubu T, Mifune Y, Inui A, Takase F, Ueda Y, Kataoka T, Kurosaka M: Characterization of progenitor cells derived from torn human rotator cuff tendons by gene expression patterns of chondrogenesis, osteogenesis, and adipogenesis.J Orthop Surg Res 2016, 11:40.

24. Hu J, Zhang T, Xu D, Qu J, Qin L, Zhou J, Lu H: Combined magnetic fields accelerate bonetendon junction injury healing through osteogenesis.Scand J Med Sci Sports 2015, 25:398-405.

25. Lu H, Hu J, Qin L, Chan KM, Li G, Li K: Area, length and mineralization content of new bone at bonetendon junction predict its repair quality.J Orthop Res 2011, 29:672-677.

26. Yu MD, Su BH, Zhang XX: Morphologic and molecular alteration during tibia fracture healing in rat.Eur Rev Med Pharmacol Sci 2018, 22:1233-1240.

27. Lu H, Qin L, Cheung W, Lee K, Wong W, Leung K: Low-intensity pulsed ultrasound accelerated bonetendon junction healing through regulation of vascular endothelial growth factor expression and cartilage formation.Ultrasound Med Bio/ 2008, 34:1248-1260.

28. Zhu W, Kim J, Cheng C, Rawlins BA, Boachie-Adjei O, Crystal RG, Hidaka C: Noggin regulation of bone morphogenetic protein (BMP) 2/7 heterodimer activity in vitro.Bone 2006, 39:61-71.

29. Gazzerro E, Gangji V, Canalis E: Bone morphogenetic proteins induce the expression of noggin, which limits their activity in cultured rat osteoblasts.J Clin Invest 1998, 102:2106-2114.

30. Pizette S, Niswander L: BMPs are required at two steps of limb chondrogenesis: formation of prechondrogenic condensations and their differentiation into chondrocytes.Dev Bio/ 2000, 219:237- 
249.

31. Ma CB, Kawamura S, Deng XH, Ying L, Schneidkraut J, Hays P, Rodeo SA: Bone morphogenetic proteins-signaling plays a role in tendon-to-bone healing: a study of rhBMP-2 and noggin.Am J Sports Med 2007, 35:597-604.

\section{Figures}

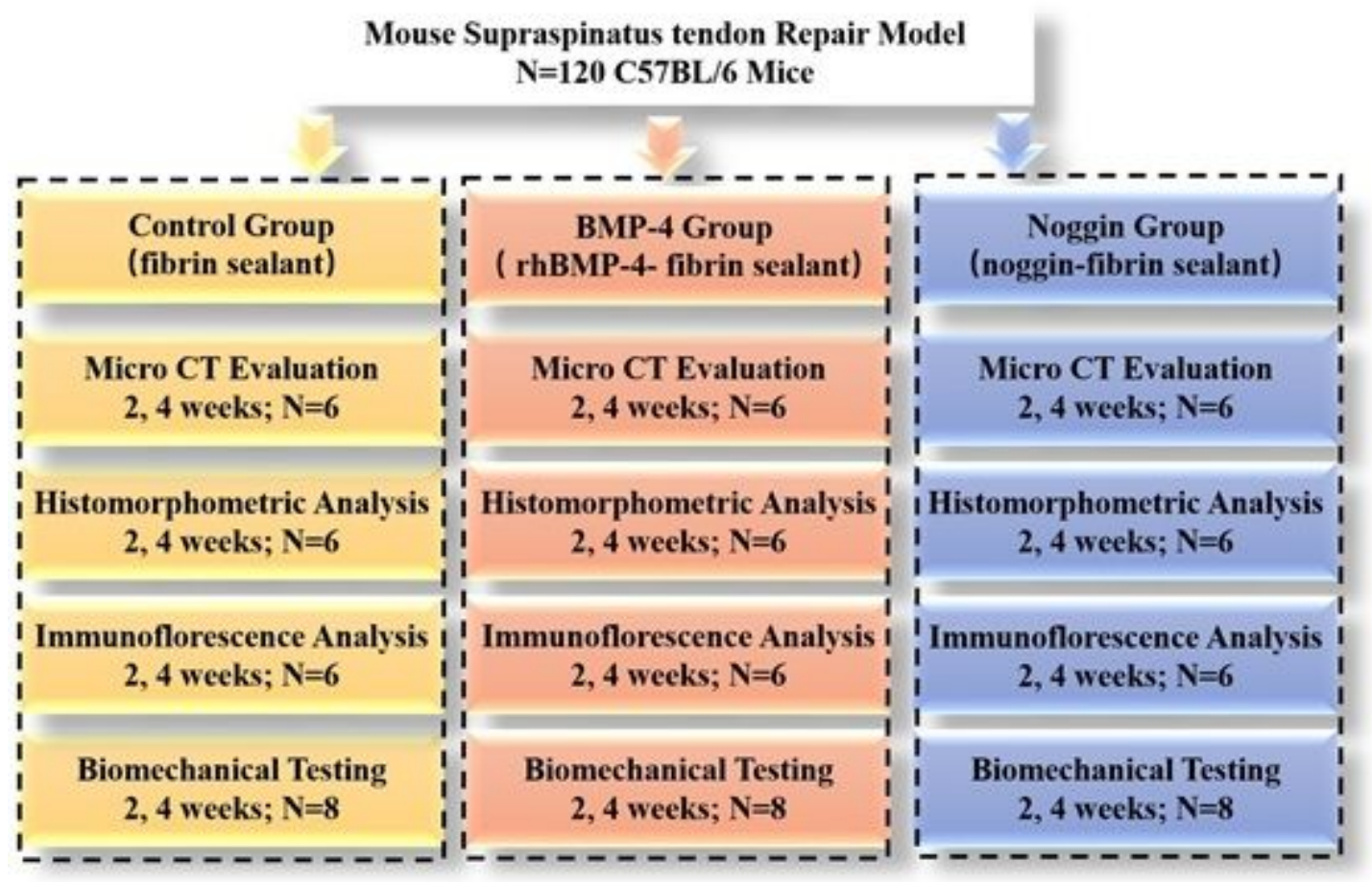

Figure 1

Study design. 